\section{Foetal brain development in offspring of women with psychosis}

\author{
MARY C. CLARKE, MARY CANNON, MATTHEW HOGG, \\ MAUREEN N. MARKS, SUE CONROY, SUSAN J. PAWLBY, \\ ANNE GREENOUGH and KYPROS NICOLAIDES
}

\begin{abstract}
Summary Cerebral ventricular enlargement and reduced cortical volume are correlates of chronic schizophrenia.We investigated whether genetic risk for psychosis is related to differences in foetal brain development as measured by prenatal ultrasonography. Routine foetal cerebral measures at 19-23 weeks of gestation were compared between the offspring of 35 women with a history of psychosis and 105 control women matched for gestational age. Overall, no significant differences were found between the highrisk and control groups. There was a nonsignificant trend in the adjusted analysis towards increased lateral ventricular width in the offspring of mothers with psychosis.
\end{abstract}

\section{Declaration of interest None.}

Funding detailed in Acknowledgements.

Cerebral ventricular enlargement and reduced cortical volume are now wellreplicated correlates of chronic schizophrenia (Wright et al 2000) and can be detected at the time of first presentation for treatment (Cahn et al, 2002). It is therefore likely that brain changes can be found much earlier in the disease process - perhaps even in foetal life. Pinpointing the time during development when abnormalities are first evident will have implications for investigating the causal pathways to later psychotic illness and identifying developmental genes that might be operating (Cannon \& Clarke, 2005).

The aim of this study was to determine whether genetic risk for psychosis was related to observable differences in foetal brain development as measured by ultrasound. Our hypothesis was that the high-risk offspring would show increased lateral ventricular volume and decreased cerebral volume measurements compared with controls.

\section{METHOD}

\section{Study design}

This was a case-control study using foetal scan records from archives. Foetal scan data were retrieved for women with a prior diagnosis of psychotic disorder who had attended King's College Hospital London for antenatal care between 1998 and 2002. From a search of referral records to the hospital perinatal psychiatry service over the same period, we identified 80 women with a history of psychotic disorder, including schizophrenia, schizoaffective disorder, bipolar disorder and post-partum psychosis. We were able to retrieve foetal scan data from the antenatal scan database for 35 of these women. The next three women, matched for gestational age, who were scanned after each index woman were taken as the control group $(n=105)$.

Information on maternal age, height, weight, ethnicity and parity was obtained from the database for both groups.

This study was approved by the ethics committees of King's College Hospital and the Institute of Psychiatry, London.

\section{Foetal scanning}

Routine second-trimester scanning for foetal anomalies was performed between 19 and 23 weeks of gestation at King's College Hospital. The foetal scan report gives detailed measurements of the foetus and details of any abnormalities detected. Sonography measurements were made according to standardised procedures (Snijders \& Nicolaides, 1994).

We extracted the following measurements of foetal cerebral growth from the scan report: biparietal diameter, head circumference, cisterna magna size, transcerebellar diameter and lateral ventricular width (the width of the posterior horn of the lateral ventricle measured at its widest point). Measures of overall foetal growth included femur length and abdominal circumference.

\section{Statistical analysis}

$T$-test and $\chi^{2}$ test were used to compare foetal growth measures and maternal characteristics between the two groups. Conditional logistic regression analyses were performed to estimate the odds for being in the high-risk group for each unit change in foetal cerebral structures. Regression analyses were carried out using STATA version 8 for Windows.

\section{RESULTS}

\section{Foetal growth}

The two groups were well matched for mean gestational age at the time of the scan: 154 days (s.d.=9.5) for women with a history of psychotic illness $v .155$ (s.d.=9.2) for controls. There were no significant differences in mean foetal femur length $(37.9 \mathrm{~mm}$, s.d. $=4.8 v .37 .3 \mathrm{~mm}$, s.d. $=4.0 ; t=-0.706 ;$ d.f. $=135, P=0.48$ ) or foetal abdominal circumference $(173.2 \mathrm{~mm}$, s.d. $=0.5$ v. $171 \mathrm{~mm}$, s.d. $=$ $16.1 ; t=-0.691$, d.f. $=135, P=0.49$ ), indicating that there was no difference in overall foetal growth between the groups.

\section{Maternal characteristics}

Mothers with a history of psychiatric illness tended to be older (mean age 30.8 years, s.d. $=5.8 v$. 30.1, s.d. $=6.1$ ); heavier (mean weight $72.3 \mathrm{~kg}$, s.d. $=17.8$ v. 67.5 , s.d.= 12.7); shorter (mean height $157.9 \mathrm{~cm}$, s.d. $=26.4 v .165 .3 \mathrm{~cm}$, s.d.=9.6); and had greater parity (mean 1.2 children, s.d. $=1.5$ $v$. 0.75 , s.d. $=1.2$ ). Only the difference in height was statistically significant $(t=2.123$, d.f. $=103, P<0.05)$. There was no significant difference in ethnicity between the two groups $\left(\chi^{2}=2.686\right.$, d.f. $=2$, $P=0.26$ ), but ethnic group was recorded for only three-quarters of the sample.

Table 1 presents odds ratios unadjusted and adjusted for maternal characteristics and measures of overall foetal growth. There were no significant differences between the groups for any of the foetal cerebral measurements in the unadjusted analysis. The adjusted analysis revealed a trend $(P=0.06)$ for lateral ventricular size to be associated with genetic risk for psychosis. A unit increase in lateral ventricle width led to a 2.2-fold increase in the adjusted odds of being the offspring of a mother with a history of psychosis. Adjustment for parity differences between the groups contributed most strongly to this finding. On further examination, we found 
a significant negative correlation between ventricle width and parity among women with a history of psychosis, such that each unit increase in parity led to a corresponding decrease in ventricle width. Ventricular width was greatest when mothers had had no previous pregnancies $(7.3 \mathrm{~mm})$. The comparison figure for the control group was $6.7 \mathrm{~mm}$.

\section{DISCUSSION}

We found no significant overall differences in foetal cerebral measures between the group at high genetic risk for a psychotic disorder and the control group. However, the trend towards increased lateral ventricular width in the high-risk group is in keeping with our hypothesis and with studies indicating a relationship between increased foetal ventricular width and childhood neurodevelopmental disorders (Gilmore et al, 2001). The finding of increased ventricular width in first-born children of mothers with psychosis is also consistent with the increased risk of psychosis in firstborn children (Kemppainen et al, 2001; Haukka et al, 2004). This, to our knowledge, is the first published report on foetal brain development in those at high risk for psychosis. A strength of our study is the high quality of the foetal ultrasound data. King's College Hospital (which incorporates the Harris Birthright Centre) is a centre of excellence in foetal medicine in the UK with sonographers that are trained to a high level in standardised ultrasonography techniques (Snijders \& Nicolaides, 1994).

There are a number of limitations of the study. First, the small number of cases reduced the power to find a significant

MARY C. CLARKE, BA, PhD, MARY CANNON, MD, PhD, Department of Psychiatry, Royal College of Surgeons in Ireland, Dublin, Ireland; MATTHEW HOGG, MD, Harris Birthright Research Centre for Foetal Medicine, King's College Hospital, London, MAUREEN N. MARKS, DPhil, Divison of Psychological Medicine, Institute of Psychiatry, London, SUE CONROY, MSc, SUSAN J. PAWLBY, MA, PhD, Section of Perinatal Psychiatry, Institute of Psychiatry, London, ANNE GREENOUGH, MD, Division of Asthma, Allergy and Lung Biology, King's College London, KYPROS NICOLAIDES, MD, Harris Birthright Research Centre for Foetal Medicine, King's College Hospital, London, UK

Correspondence: Dr Mary Clarke, Department of Psychiatry, Royal College of Surgeons in Ireland, RCSI Education and Research Centre, Beaumont Hospital, Dublin 9, Ireland. Email: maryclarke@rcsi.ie

(First received I March 2006, final revision 22 December 2006, accepted 22 January 2007)

association. Second, second-trimester scan data were missing for a large proportion of the high-risk group and since it is likely that the women who did not attend for their scan were more severely ill, this would have resulted in underestimating the differences between the groups. Third, we lacked information on maternal socio-economic status, smoking and pregnancy complications, which are likely to differ between the groups and might also affect foetal brain development (Yoshida et al, 1999; Cannon et al, 2002). Finally, we lacked sufficient diagnostic information to allow us to carry out a subgroup analysis.

We recommend that future studies should be prospective and include detailed maternal diagnostic and demographic information.

\section{ACKNOWLEDGEMENTS}

M. Cannon is supported by NARSAD (2002 Grable Investigator Award), The Wellcome Trust and The Health Research Board (Ireland).

\section{REFERENCES}

Cahn, W., Hulshoff Pol, H. E., Lems, E. B. et al (2002) Brain volume changes in first-episode schizophrenia: a I-year follow-up study. Archives of General Psychiatry, 59, $1002-1010$.

Cannon, M. \& Clarke, M. C. (2005) Risk for schizophrenia - broadening the concepts, pushing back the boundaries. Schizophrenia Research, 79, 5-13.

Cannon, M., Jones, P. B. \& Murray, R. M. (2002) Obstetric complications and schizophrenia: historical and meta-analytic review. American Journal of Psychiatry, 159, 1080-1092.

Gilmore, J. H., van Tol, J. J., Lewis Streicher, H., et al (200I) Outcome in children with fetal mild ventriculomegaly: a case series. Schizophrenia Research, 58, 219-226.

Haukka, J. K., Suvisaari, J. \& Lonnqvist, J. (2004) Family structure and risk factors for schizophrenia: case-sibling study. BMC Psychiatry. 27, 41.

Kemppainen, L., Veijola, J., Jokelainen, J., et al (200I) Birth order and risk for schizophrenia: a 31-year followup of the Northern Finland 1966 Birth Cohort. Acto Psychiatrica Scandinavica, 104, 148-152.

Snijders, R. J. \& Nicolaides, K. H. (1994) Fetal biometry at 14-40 weeks' gestation. Ultrasound in Obstetrics and Gynecology, 4, 34-48.

Wright, I. C., Rabe-Hesketh, S., Woodruff, P. W., et al (2000) Meta-analysis of regional brain volumes in schizophrenia. American Journal of Psychiatry, 157, 389-387.

Yoshida, K., Marks, M. N., Craggs, M., et al (1999) Sensorimotor and cognitive development of infants of mothers with schizophrenia. British Journal of Psychiatry, 175, 380-387.

Table I The predictive value of foetal cerebral measures in identifying genetic risk for a psychotic disorder

\begin{tabular}{|c|c|c|c|c|c|c|}
\hline \multirow[t]{2}{*}{ Intracranial measure $(\mathrm{mm})$} & \multicolumn{2}{|c|}{ Mean (s.d.) } & \multirow{2}{*}{$\begin{array}{c}\text { Unadjusted } \\
\text { OR } \\
(95 \% \mathrm{Cl})\end{array}$} & \multirow[t]{2}{*}{$P$} & \multirow{2}{*}{$\begin{array}{c}\text { Adjusted OR } \\
(95 \% \mathrm{Cl})^{1,2}\end{array}$} & \multirow[t]{2}{*}{$P$} \\
\hline & $\begin{array}{c}\text { Cases } \\
(n=35)\end{array}$ & $\begin{array}{l}\text { Controls } \\
(n=105)\end{array}$ & & & & \\
\hline Biparietal diameter & $54.43(5.08)$ & $54.89(4.67)$ & $0.94(0.8 I-I . I)$ & 0.4 & $0.86(0.38-I .92)$ & 0.7 \\
\hline Cisterna magna & $5.70(0.99)$ & $5.65(1.17)$ & $1.09(0.74-1.6)$ & 0.6 & I.I2(0.7-I.64) & 0.6 \\
\hline Transcerebellar diameter & $22.81(2.40)$ & $22.65(2.18)$ & $\mathrm{I} .08(0.82-1.4)$ & 0.5 & $0.99(0.052-1.88)$ & 0.9 \\
\hline Ventricular width & $6.98(0.75)$ & $6.96(0.90)$ & $1.22(0.77-1.9)$ & 0.4 & $2.2(0.9-5.1)$ & 0.06 \\
\hline
\end{tabular}

I. Adjusted for maternal age, weight, height, parity and foetal growth (femur length and abdominal circumference).

2. Not adjusted for ethnicity owing to missing data. 